Faculdade de Ciências Econômicas UFRGS
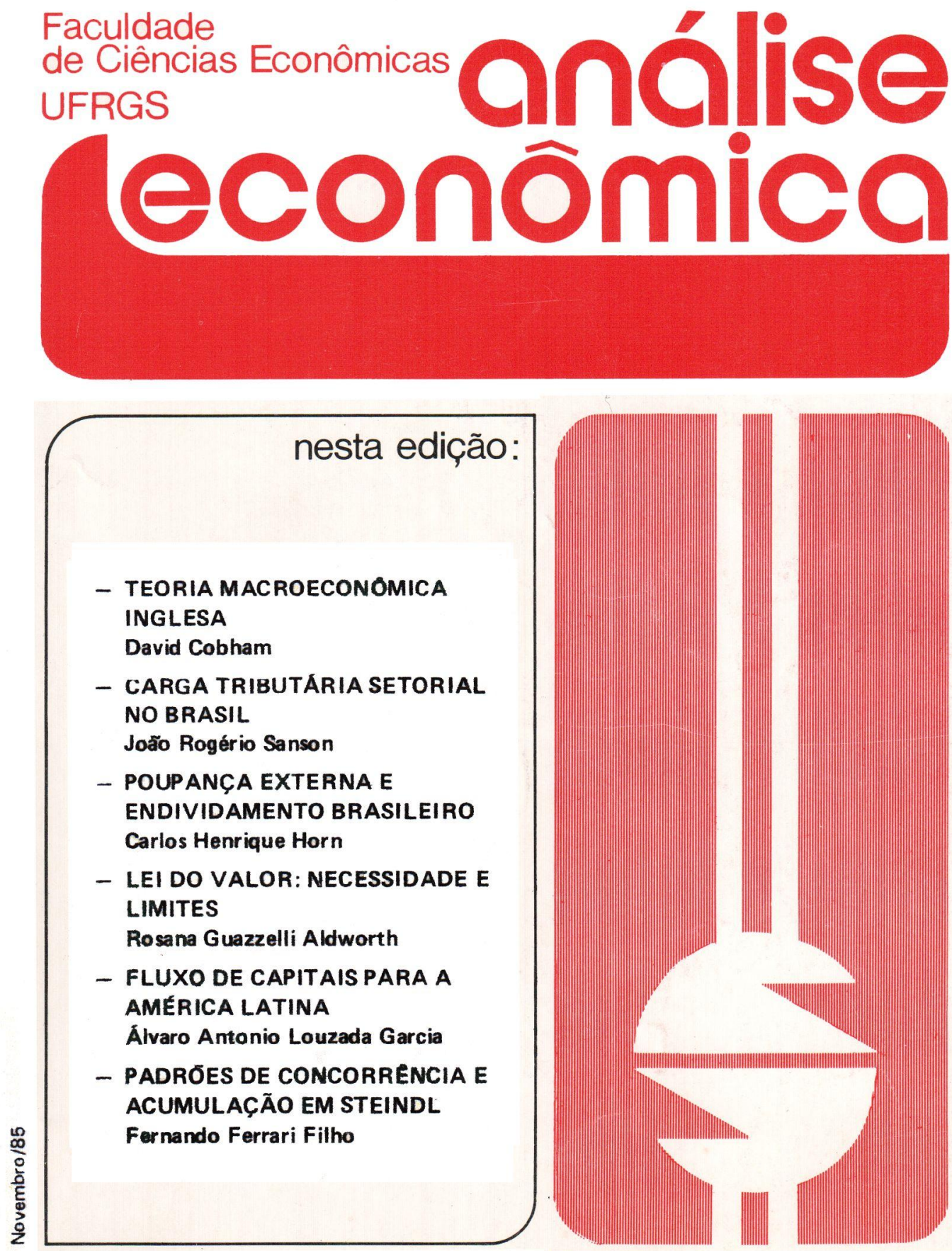

ano 3 
REITOR:Prof. Francisco Ferraz

DIRETOR DA FACULDADE DE CIÊNCIAS ECONÓMICAS:

Prof. Edgar lrio Simm

VICE-DIRETOR: Prof. Walter Meucci Nique

CHEFE DO DEPARTAMENTO DE CIENCIAS ECONOMICAS:

Prof. Renato Batista Masina

CONSELHO EDITORIAL: Prof. Pedro Cezar Dutra Fonsecs (Presidente)

Prof. Achyles Barcelos da Costa

Prof. Carlos Augusto Crusius

Prof. Claudio Francisco Accurso

Prof. Edgar Augusto Lanzer

Prof. Ernani Hickmann

Prof. Juvir Mattuella

Prof. João Rogério Sonson

Profa. Maria Imilda da Costa e Silva

Prof. Nali de Jesus de Souza

Prof. Nuno Renan L. de Figueiredo Pinto

Profa. Otilia Beatriz Kroeff Carrion

Prof. Paulo Alexandre Sphor

Prof. Roberto Camps Moraes

Profa。 Yeda Rorato Crusius

FUNDADOR: Prof. Antonio Carlos Santos Rosa

ANÁLISE ECONÔMICA publica dois números anuais nos meses de março e novembro. O preço da assinatura para 1986 é $\mathrm{Cr} \$ 20,000,00$, a ser pago através de cheque nominal para "Faculdade de Ciências Econômicas - UFRGS". Aceita-se permuta com revistas congêneres. Aceitam-se, também, livros para elaboração de resenhas ou recensões.

Toda a correspondência, material para publicação, assinaturas e permutas devem ser dirigidas a:

Prof. PEDRO CEZAR DUTRA FONSECA

Revista Análise Econômica

Avenida João Pessoa, $52-39$ andar

90.000 - Porto Alegre (RS) - Brasil 


\title{
A CARGA TRIBUTÁRIA SETORIAL NO BRASIL
}

\author{
JOÃo ROGÉRIO SÁNSON *
}

\section{INTRODUÇĀO}

O entendimento dos pontos a serem analisados no presente trabalho talvez fique mais fácil via um exemplo que dramatize as diferentes percepções do que seja .carga tributária. Assim, consideremos o caso de J.C., cujo pai era um pequeno comerciante de zona rural e, nessa condição, operava quase sempre com um caixa bastante apertado. Justamente por seu pai operar em tais condições é que J. C. ouvia suas constantes queixas sobre os recolhimentos de impostos que ele era obrigado a fazer em certos dias de cada mês. Para o pai de J.C., o recolhimento de impostos obviamente significava menos dinheiro disponível para suas despesas com a família. Não havia dúvida! Como o pagamento de impostos significava menos bens e serviços para ele e sua família, era ele, e não os seus clientes, quem arcava com os impostos.

Depois, J.C. começou a trabalhar fora e descobriu que do salário, combinado com o seu empregador, uma parte era descontada e ficava na empresa. Foi-the explicado que o desconto cobria uma espécie de seguro obrigatório para aposentadoria e problemas de saúde. A empresa providenciaria o recolhimento em seu nome. Houve ıma certa irritação por parte de J.C., pois, como era jovem

\footnotetext{
* Professor do Departamento de Ciências Econômicas e do Curso de Pós-Graduação em Economia da Universidade Federal do Rio Grande do Sul-UFRGS. Nersão revista de trabalho apresentado à Federação das Associações Comerciais do Rio Grande do Sul.
}

\begin{tabular}{|l|l|l|l|l} 
ANÁLISE ECONÓMICA & ANO 3 & Nọ5 & NOV./1985 & p. 23-38 \\
\hline
\end{tabular}


e saudável, preferia gastar aquele dinheiro logo, sem ter que esperar uma eternidade para usufru $1-10$. Nesse caso, não havia dúvidas sobre quem pagava o seguro-imposto: era J.C. e não a empresa.

Chegou o dia em que J.C. decidiu comprar o seu aparelhinho de som. Ao olhar com mais cuidado para a nota fiscal, deparou com a discriminação em separado do ICM. Ficou então sabendo que quase $20 \%$ do valor pago pelo aparelhinho era de imposto e, pelo jeito, estava saindo do bolso dele. Afinal, o sacrifício que ele fizera para aquela compra poderia ter sido bem menor se ele não tivesse que pagar o imposto. Para ele, era indiferente que o recoIhimento fosse feito pela empresa, como no caso do seguro-imposto.

Enquanto desfrutava do prazer de ouvir seus discos preferidos, continuou a pensar sobre as coisas que poderia ter comprado com aquele imposto que pagara. Foi então que se lembrou das queixas do seu pai. Sim, seu pai também recolhia o ICM e achava que o ônus do imposto recaía sobre ele e não sobre os seus fregueses. Se ele fosse discutir o assunto com o velho, possivelmente poderiam terminar pensando que estaria havendo conflito entre gerações. Felizmente para a paz familiar, ele esqueceu o assunto e foi cuidar de seu aparelho de som.

O que J.C. não sabia é que com este tipo de preocupação estaria em companhia de muitas gerações de economistas, pelo menos neste último século. O problema de saber quem efetivamente arca com a despesa pública tem sido um dos problemas básicos analisados por eles.

Pode-se ver então que a percepção do assalariado ou do consumidor pode estar em conflito com a visão do empresário. Afinal de ccntas, quem realmente arca com o ônus do imposto? Talvez haja alguma diferença entre recolher o imposto para o fisco e efetivamente arcar com o imposto. Este traijalho procurará esclarecer estes pontos, ao mesmo tempo que apresentará alguns dados disponíveis sobre o assunto.

O estudo da distribuição da carga tributária pode ser feito de diferentes formas, como, por exemplo, o efeito por classe de renda. No presente caso, contudo, o interesse centra-se nos setores produtivos.

A noção de carga tributária representa a percentagem de alguma base que é paga na forma de impostos. $O$ empresário às vezes pode usar como base o faturamento ou então o lucro da sua empresa. Independentemente, contudo, de qual base ele use, a sua preocupação, ao falar em carga tributária, é saber até que ponto 
ele está arcando com as despesas públicas, em comparação com os demais membros da sociedade.

Na próxima seção, será esclarecido o aparente paradoxo entre a visão do empresário e a do consumidor, qualificando-se melhor o significado do coeficiente de carga tributária. Deverá ficar claro, também, qual é a base mais adequada para as discussões de justiça fiscal. Na seção seguinte, serão apresentados alguns dados sobre a carga tributária a nível nacional, fazendo-se inclusive uma rápida comparação internacional. Por fim, na última seção, serão apresentados alguns dados disponíveis sobre a carga tributária setorial.

\section{A CARGA TRIBUTÁRIA E A INCIDENCIA}

Já se definiu acima carga tributária como a percentagem de alguma base que é paga na forma de impostos. O exemplo dado foi da receita total de uma firma como a base. Note-se que nos exemplos iniciais sobre o empresário e o trabalhador cada um tinha uma base em mente. No caso do empresário, provavelmenre ele estava pensando na sua receita líquida, isto é, naquilo que efetivamente sobrava para seus gastos pessoais e para reinvestimento. Já para o trabalhador, a base provavelmente seria o seu salário.

Contudo, no exemplo inicial, havia um paradoxo. Tanto o empresário como o consumidor achavam que estavam pagando o mesmo imposto, no caso o ICM. O empresário era quem recolhia, porém o consumidor via o valor do ICM como um acréscimo ao valor do bem comprado. A resolução do paradoxo surge se for lembrado que pode ser possivel à firma passar para a frente o imposto, isto é, jogar o imposto no preço como um dos custos. Se isto for feito integralmente, quem arca com o imposto é o consumidor. Nesse caso, o consumidor deixa de consumir individualmente para que a sociedade consuma coletivamente. É como se do volume de recursos humanos e físicos disponíveis para um consumidor fosse tirada uma parte para ser usada na produção de bons e serviços de consumo coletivo.

Porém, fica a possibilidade de a firma não conseguir passar para a frente integralmente, na forma de custos, o valor do imposto. No momento de se determinar o preço de venda de uma mercadoria, o imposto não se distingue dos dernais itens de custos. Embora a empresa procure obviamente cobrir os seus custos, cobrando o maior preço possível em função do que os compradores aceitam e em funçăo do que os concorrentes estão cobrando, a remu- 
neração do capital investido no negócio será o item residual nos custos. E claro que a empresa, ao buscar o maior preço que o mercado permita, busca uma remuneração para o seu capital que seja, no longo prazo, superior ao que daria o mercado financeiro. Caso contrário, seria preferível fechar o negócio e mudar de ramo ou simplesmente viver de renda. E justamente este caráter residual da remuneração do capital próprio que faz com que haja um elemento amortecedor na hora de se determinar preços de venda.

Imagine-se um setor industrial que opere num ambiente altamente competitivo, mas com a capacidade instalada sendo usada integralmente e sem possibilidade de expansão. A introdução de um imposto levaria as firmas a tentarem passá-lo para a frente via aumento de preços. Porém, um aumento de preços acima da inflação leva, via de regra, a quedas na quantidade demandada daquele produto. Ora, algumas firmas ficarão com excesso de capacidade, com a conseqüente queda na remuneração do capital próprio. A reação no caso de empresas bastante competitivas é tentar baixar o preço com o objetivo de aumentar as suas vendas. Porém, dada a competitividade, todas tentarão a mesma coisa e o resultado será uma queda na receita miédia de cada firma. No final, o preço da mercadoria será o mesmo que antes, mas a receita média, líquida, do imposto, será exatamente menor pelo valor do imposto. Se o imposto fosse de $10 \%$ sobre o preço de venda, este preço continuaria o mesmo, mas a receita média líquida seria aproximadamente 9\% menor. Em tal caso, a permanência das empresas no mercado dependerá da capacidade de absorção deste ônus. Uma das formas de absonver tal queda de preço é via uma menor remuneração do capital próprio. Mas o que interessa aqui é que se tem un caso em que o imposto não é passado para frente.

Nesta situaçăo, a firma recolhe o imposto e ele entra nos seus custos, mas quem realmente arca com o ônus ciele são os donos do capital próprio da firma. No caso de sociedades administradas por administradores profissionais, pode-se dizer que, na verdade, $0 \mathrm{im}$ posto foi passado para trás. Em vez de a firma passar o imposto para os compradores de seus produtos, ela o repassa para os donos do capital que utiliza.

Esta situação em que a firma pode repassar o imposto para os donos de seu capital ajuda a entender que é também possível à firma tentar repassar o imposto sobre suas vendas para qualquer das firmas ou pessoas que vendam bens ou serviços a ela. Por exemplo, no caso acima as empresas poderiam tentar baixar seus custos, não via diminuiçăo da remuneração do capital próprio, mas via substi- 
tựção de mão-de-obra, de forma a baixar o salário médio da firma. Isto pode ser factível em oćasiões de crise, quando há excesso de mão-de-obra em quase todas as especialidades funcionais. Naturalmente, isto envolve custos tais como possíveis baixa de qualidade dos produtos, despesas e dispensa e recontratação de pessoal, etc.

Entre esses dois casos extremos, em que o imposto é passado integralmente para frente ou para trás, está naturalmente a maioria dos casos em que deve haver participação em diferentes graus, tanto do lado das vendas como das compras.

Fica claro, então, que o conceito de carga tributária vai depender não só da definição dos valores transferidos ou não de um imposto, mas também da base em relação à qual se calcula o coefi. ciente. Por isso, ao se interpretar o conceito de carga tributária é preciso verificar quais as suposições explícitas ou implícitas acerca do grau de transferência dos impostos em consideração.

$\mathrm{Na}$ literatura mais técnica da área de finanças públicas, esta noção de carga tributária, que leva em consideração quem efetivamente arca com o ônus tributário, é conhecida como incidência. Reserva-se, às vezes, o termo carga tributária para o coeficiente de recolhimento de împosto em relação à base legal. Porém, para fins do presente trabalho, será mantida a terminologia de carga tributária como também significando incidência, dadas as devidas qualificações.

Após essa explicação sobre o que é carga tributária, é preciso mencionar ainda que o grau de transferência dos impostos por parte de quem os recolhe depende, em parte, dos prazos disponíveis para os devidos ajustes e também das flutuações no nível geral de atividade.

Logo após a introdução de um novo imposto, é provável que ele incida totalmente sobre quem é obrigacio a recolheĭ. Porém, com o passar do tempo, poderá ser possível ajustar compras, vendas e preços de modo a passar para a frente pelo menos parte do imposto. Assim, ao se falar sobre carga tributária setorial é preciso distinguir entre os prazos, especialmente quando da introdução recente de novos impostos ou da alteração de alíquotas de impostos já existentes. No presente trabalho, fala-se de impostos que existem há bastante tempo, com exceção, talvez, do FINSOC!AL e de recentes aumentos de alíquotas do IAPAS e do IOF. Contudo, em relação ao bolo total de arrecadação do País, tais alterações são pequenas e, portanto, a visão de longo prazo é a mais adequada.

Flutuações no nível geral de atividades da economia, em princípio, afetam igualmente todos os setores produtivos da economia 
e, portanto, náo a afetam o diferencial de incidencia entre os grupos sociais. Porém, há exceçōes e é possível que as flutuações sejam diferenciadas entre os setores. Agora mesmo, o setor exportador brasileiro está crescendo mais rápido do que o resto da economia. Isto pode ter efeitos sobre os graus de transferência dos impostos, com aqueles setores que encontram condições de demanda mais favoráveis podendo passar para a frente impostos que anteriormente não podiam fazê-lo. Como tais flutuações são, em geral, vistas como de curto prazo, em contraposição às tendências de crescimento de longo prazo, é preciso ter bem claro qual é o horizonte que se está considerando. $O$ presente trabalho não considerará este efeito de flutuações do nível geral de atividades, porém ele pode ser relevan. te em discussões a nível de setores, especialmente quando se considera a introdução de novos impostos. Da mesma forma, poderia ser também relevante o estudo das alterações inflacionárias nos preços desile que os setores produtivos sejam afetados diferenciadamente. Como se sabe, o impacto da inflação sobre a renda real de cada um depende essencialmente do controle e da velocidade com que cada agente econômico pode afetar os preços daquilo que vende em relação àquilo que compra.

Em resumo, o conceito de carga tributária precisa ser qualificado pela possibilidade da transferência para a frente do imposto recolhido por uma firma e/ou indivíduo. Assim, antes do cálculo da carga, seria preciso verificar qual é a verdadeira contribuição ao bolo das despesas públicas. Além disso, é preciso lembrar que a contribuição cie carla um pode variar com o tempo. A transferência pode não ocorrer imediatamente, mas só após ajustamentos que nem sempre podem ser feitos logo após as alterações tributárias. E preciso lembrar também que o grau de transferência pode variar se houver efeito diferenciado das flutuações no nível geral de atividades sobre os individuos ou setores da economia.

\section{A CARGA TRIBUTARIA NACIONAL}

Como introdução ao estudo da carga setorial, será estudada agora a carga a nível nacional. Após a discussão do que se entende por este tipo de carga tributária e da apresentação de dados disponíveis sobre o Brasil, será feita uma rápida comparação internacional.

A primeira noção a ser considerada é a da Renda Nacional. E em referéncia a essa base que se falará na carga tributária nacional. 
Num sentido bem geral, ela significa a soma dos valores pagos a quem participou da produção num determinado período, contribuindo com fatores produtivos. Subtrai-se daí o valor líquido de pagamentos a fatores de outros países. Alternativamente, avalia-se o total de bens e serviços disponíveis para utilização final dos consumidores, do governo e para capitalização. O valor da renda é igual ao do produto, exceto por pequenos ajustamentos. Assim é que, mesmo se pensando em termos de renda, trabalha-se às vezes com a noção de produto.

A carga tributária, a nível nacional, mostra a contribuição média de cada cruzeiro de renda para as despesas públicas. Como não se distingue entre classes de renda ou entre outros agrupamentos, trata-se da contribuição média de cada um a partir da sua renda.

Para os estudos da carga tributária a esse nível, a possibilidade de transferência de impostos de um grupo a outro é irrelevante, pois está-se olhando para o agregado de renda. Porém, é possível a um país passar para frente parte dos seus impostos via comércio exterior, dependendo das condições de competitividade e da importância relativa do país nos diferentes mercados. Quanto à possibilidade de se importar impostos, eles estariam embutidos no preço dos bens e serviços importados e não haveria necessidade de correções por conta deles. Do ponto de vista nacional, eles seriam apenas um custo adicional às importações. E só o imposto exportado que envolve uma participação externa do financiamento das despesas públicas do país. Contudo, para o caso brasileiro, não se conhece nenhum estudo que tenha feito tais correções. De qualquer modo, ele deve ser pequeno em relaçao ao total da carga tributária, por conta dos rebatimentos de impostos dados às expcrtações e nela própria participação relativamente pequena das exportações no produto nacional.

A carga tributária brasileira, a nível nacional, está apresentada na Tabela 1, para o período 1965 a 1980. Trata-se de dados computados por Carlos A. Longo. Observa-se que, no período, a arrecadação total do governo brasileiro, incluindo os três níveis, flu. tuou entre 19 e $25 \%$ do Produto Interno Bruto. Isto quer dizer que, nesse período, de cada cruzeiro de renda gerado no País, aproximadamente vinte centavos foram destinados ao financiamento dos gastos públicos, via tributação. Esta informação não inclui a transferência de recursos por via inflacionária, onde, via emissões monetárias, o governo amp!ia, num primeiro momento, o poder de compra de suas receitas. Contudo, é a informação mais 
proxima possivel da noção de carga tributária, na forma detinida acima, em que se busca saber a contribuição média de cada individuo para as despesas públicas.

TABELA 1 - BRASIL: CARGA TRIBUTARIA EM RELAÇÃO AO PIB - 1965 a 1980

(\%)

\begin{tabular}{lc}
\hline ANO & CARGA TRIBUTARIA \\
\hline 1965 & 19,1 \\
1966 & 21,8 \\
1967 & 20,8 \\
1968 & 22,9 \\
1969 & 24,2 \\
1970 & 24,0 \\
1971 & 22,3 \\
1972 & 24,4 \\
1973 & 24,8 \\
1974 & 24,2 \\
1975 & 23,9 \\
1976 & 23,8 \\
1977 & 24,5 \\
1978 & 24,0 \\
1979 & 22,6 \\
1980 & 21,9 \\
\hline
\end{tabular}

Fonte:Carlos A. Longo, Nota sobre a evolução da carga fisćal no Brasil. Revista de Economia Política, 4(4): 124-134, out./dez. 1984, Ver p. 127.

Como se compara esta carga com! a de outros países? O próprio Longo faz esta comparação. A Tabela 2 reproduz a carga cributária média para os países da OCDE, em, comparação com valores brasileiros para os mesmos anos. É óbvio que a carga tributária nesses paŕses é bem maiór que a brasileira.

Observe-se que as empresas estatais ficaram fora da análise acima, pois suas receitas de vendas de bens e serviços obviamente não constituem taxação. Nesse caso, há contrapartida direta de bens e serviços, tal como no setor privado. Naturalmente, a exclusão das estatais no estudo de carga tributária não tira a importância de tal participação em discussões sobre o grau de controle estatal do volume de recursos da economia. A natureza do controle, contudo, é bem diferente num e noutro caso. A tributaçao envolve umá apropriação compulsória de recursos para a produção de bens e serviços ou para a redistribuição de rendas, sem que necessariamente esse 
uso coincida com as preferências do contribuinte. Já no caso das estatais, há sempre um bem ou um serviço em troca, como, por exemplo, o aço ou o serviço de correio. •

TABELA 2 - CARGA TRIBUTARIA MÉDIA EM RELAÇAO AO PIB:

PAISES DA OCDE E BRASIL.

\begin{tabular}{|c|c|c|}
\hline \multirow[b]{2}{*}{ ANO } & \multicolumn{2}{|c|}{ CARGA TRIBUTÁRIA } \\
\hline & OCDE & BRASIL \\
\hline 1955 & 24,7 & - \\
\hline 1960 & 26,2 & - \\
\hline 1965 & 28,0 & 19,1 \\
\hline 1970 & 31,9 & 24,0 \\
\hline 1975 & 34,6 & 23,9 \\
\hline 1980 & 36,6 & 21,9 \\
\hline
\end{tabular}

Fonit: Carlos A. Longo, Nota sobre a evolução da carga fiscal no Brasil. Revista de Economia Política, 4(4): 124-134, out./dez./1984. Ver p. 128.

Obs.: A OCDE inclui Alemanha, Itália, Áustria, Grã-Bretanha, Noruega, Nova Zelândia, Finlândia, Países-Baixos, Suécia, Bélgica, Estados Unidos, Dinamarca, Austrália, Irlanda, Canadá, Suiça, Japão e Portugal.

\section{A CARGA TRIBUTÁRIA SETORIAL}

Após as discussões sobre a carga tributária do ponto de vista individual e nacional, discute-se agora o mesmo conceito do ponto de vista de um setor qualquer da economia. Em seguida, serãn apresentados alguns dados disponiveis sobre este tipo de carga tributária.

Que sentido há em se falar sobre a carga tributária de um determinado setor da economia? Tome-se, como exemplo, um caso extremo em que nada do imposto cobrado de um setor é transferível para frente. Contudo, tais impostos ainda podem ser transferidos para os vendedores de bens e serviços àquele setor. Pode-se restringir o exemplo mais ainda para o caso em que o imposto é transferível apenas para os trabalhadores e para os donos do capital investido no setor. Assim, se a carga tributária for calculada em relação à soma das remunerações de capital e de trabalho do setor, tem-se a quota de renda gerada no setor que vai para o bolo que financia as despesas públicas. Porém, se o imposto for integralmente 
transferido para a frente, o setor, em princípio, não terá contribuído para aquele bolo, mesmo tendo recolhido. Num caso de transferéncia parcial para a frente, seria preciso estimar o quanto do imposto foi transferido. A parte não transferida seria então a que seria utilizada para o cálculo da carga tributária. Mas, isto não é tudo.

Os trabalhadores e os donos do capital de um dado setor, ao gastarem o seu rendimento, estarão sujeitos aos impostos que incidem diretamente sobre estes ganhos e aos impostos que cada setor transfere para a frente ao fazerem suas vendas para eles. Assim, a carga tributária de um setor, num sentido rigoroso, precisaria ser calculada com relação aos indivíduos ligados ao setor. Em caso contrário, ficaria de fora aquela contribuição que a renda gerada no setor faz para as despesas públicas por via indireta. Um estudo deste tipo seria bastante dispendioso, dado que seria preciso conhecer a estrutura de gastos e de investimentos dos indivíduos ligados a um dado setor, classificá-los por classe de rendimento e verificar então como a estrutura tributária os afeta.

Num sentido mais prático, contudo, deve-se lembrar que a permanência ou não de uma firma num determinado setor será decidida pelos donos do capital investido nas firmas do setor. Os impostos afetam a rentabilidade do capital. Logo, os impostos devem at etar também a decisão sobre a permanência do capital no setor. Assim, pode-se perguntar qual seria a carga tributária sobre os ganhos desse capital. Seria a carga tributária diferenciada entre setores que afetaria a alocação intersetorial de capital. De forma mais específica, o argumento é que a carga tributária direta sobre os rendimentos do capital gerados nas empresas é que afetaria a alocação intersetorial de capita! e não a carga que ainda teriam os donos do capital ao consumirem ou reinvestirem iais rendinentos fora da empresa, por conta de transferências para a frente por parte daquelas que vendem para eles. Essa é a noção de carga tributária setorial que se terá em mente daqui por diante.

Entretanto, para o estudo da carga tributária de um setor é preciso discutir, mesmo que de forma bastante geral e rápida, quais as suposições usuais sobre o grau de transferência dos principais impostos brasileiros. Diz-se suposições usuais porque tal assunto é ainda bastante controverso, não apenas por conta dos aspectos emocionais de se dizer quem efetivamente arca com as despesas públicas, mas principalmente pelo tipo de informações quantitativas da economia que estão disponíveis, mesmo nos países mais desenvolvidos. Seriam precisos modelos da economia bem mais detathados do que os já existentes. 
Antes, porém, de se discutir o grau de transferência, é conveniente verificar a importância relativa dos principais impostos brasileiros. Tal importância relativa pode ser verificada através da Tabela 3. Embora a estrutura apresentada seja de 1975, não deve ter havido mudanças significantes, exceto, talvez, pelo crescimento de importância do Imposto de Renda em relação ao IPI. Os principais impostos brasileiros são: ICM, IPI, Imposto de Renda, FGTS e PIS/PASEP e as Contribuições à Previdência. Em 1975, estes im. postos representaram $82,1 \%$ do total arrecadado no País. Os impostos sobre vendas de bens e serviços, entre os quais estão o IPI, ICM, Imposto Único sobre Combustíveis e Lubrificantes (IUCL), Imposto Sobre Importações e o Imposto Sobre Serviços de Qualquer Natureza (ISSON), representaram, por sua vez, aproximadamente 45,5\%. Este último cálculo é dito aproximado por não ter sido possível incluir o PIS-faturamento, o Imposto sobre Operaçōes Financeiras e os demais Impostos Únicos, por não estarem discriminados.

TABELA 3 - BRASIL: COMPOSIÇAO DA RECEITA TRIBUTÁRIA POR NIVEL DE GOVERNO E PRINCIPAIS IMPOSTOS - 1975

\begin{tabular}{lcr}
\hline NIVEL DE GOVERNO & & \\
E & BILHOES DE CRUZEIROS & $\%$ \\
TIPO DE IMPOSTO & & 72,1 \\
\hline UNIÄO & 179,2 & 14,3 \\
IPI & 35,6 & 14,2 \\
FGTS e PIS/PASEP & 35,3 & 12,8 \\
Imposto de Renda & 31,8 & 10,0 \\
Contr. Prev. Empregadores & 24,9 & 7,8 \\
Contr. Prev. Empregados & 19,4 & 3,9 \\
Imp. s/Importaçōes & 9,7 & 3,3 \\
I.U.C.L. & 8,3 & 5,8 \\
Outros Tributos & 14,2 & 25,0 \\
ESTADOS & 62,1 & 23,0 \\
I.C.M. & 57,1 & 2,0 \\
Outros Tributos & 5,0 & 2,9 \\
MUNICIPIOS & 7,3 & 1,1 \\
I.P.T.U. & 2,7 & 1,0 \\
I.S.S.Q.N. & 2,6 & 0,8 \\
Outros Tributos & 2,0 & 100,0 \\
\hline TOTAL & 248,6 & 1 \\
\hline
\end{tabular}

Fonte:Fundação Getúlio Vargas, Regionalização das Transaçōes do Setor Público 1975. Rio de Janeiro, 1980.

Obs.: A classificação por nível de Governo reflete apenas os pontos de arrecadação dos diferentes impostos, ignorando, contudo, as transferencias intergovernamentais. 
De acordo cóm as hipótésés de transferência, os principais impostos podem ser agrujpados como a seguir. Um primeiro grupo seria o dos impostós sobre as vendas de bens e serviços, o que inclui - ICM, o IPI, o Imposto Sobre Importações, Impostos Únicos, o Imposto sobre Serviços e Similares. Supõe-se usualmente que estes impostos são integralmente transferidos para a frente. Esta é a suposição usada, por exemplo, por Eris et al. (1983), e também por Sanson (1980). Um segundo grupo é o do Imposto de Renda sobre as Pessoas Físicas e das Contribuições à Previdência por parte dos Empregados. Assume-se usualmente que estes impostos não são transferidos para a frente. Assim, de acordo com estas hipóteses, nenhum dos impostos destes dois grupos incide sobre a remuneração do capital. Em relação aos demais impostos, a dúvida é grande. O que muitos estudos fazem é apresentar estimativas de incidência, com nenhuma ou total transferência para a frente. Isto foi feito por Eris et al. (1983). Entre os impostos mais importantes, esse seria o caso do Imposto de Renda sobre as Pessoas Juridicas, as Contribuições à Previdência por parte dos Empregadores e as Contribuiçōes para o FGTS e PIS/PASEP. Para fins deste trabalho, adotou-se a hipótese de que as contribuições ligadas à mão-de-obra entram como parte dos custos e, como tal, são transferidas para os compradores, ou seja, há transferência integrai para a frente. Para - Imposto de Renda das Empresas, na medida em que a mobilidade intersetorial seja difícil, é provável uma menor transferência para a frente. Assume-se aqui, por simplificação, que nada é transferido para frente. Porém, como resenhado por Contador (1976) (Cap. III), as estimativas, em alguns casos, chegam até a situações em que se transfere mais do que todo o imposto para a frente, via aumentos defensivos de preços.

E com base na suposição de nenhuma traiısferência pára a frente que $F$. Rezende apresenta os seus dados, os quais estão reproduzidos aqui na Tabela 4. A tabela discrimina as taxas efetivas de imposto de renda sobre empresas, segundo o tipo de organização jurídica e por setor de atividade. A organização jurídica foi usada por Rezende como uma forma de discriminar as empresas segundo o tamanho. Isto pode não ser verdade para todos os casos, mas, de modo geral, pode-se dizer que as sociedades anônimas são maiores que as limitadas e estas, por sua vez, são maiores que as individuais. De qualquer modo, este foi o tipo de informação que ele obteve do Ministério da Fazenda à época do seu estudo.

Em relação à organização jurídica das empresas, pode-se observar que a taxa efctiva para as sociedades anônimas é menor, em 
termos médios. Tal diferença deve resultar de um aproveitamento diferenciado de deduções, abatimentos, isenções e regimes especiais de tributação, segundo Rezende. Adicionalmente, há a prática do cálculo do imposto segundo o lucro presumido para empresas de pequeno porte, concentração de um setor em regiões com incentivos fiscais ou então incentivos que envolvam depreciação acelerada do capital. Porém, como menciona Rezende, os dados disponíveis eram por demais agregados para permitir o teste destas hipóteses.

TABELA 4 - BRASIL - TAXAS EFETIVAS DO IMPOSTO DE RENDA DA PESSOA JURIDICA - ANO-BASE DE 1972

(Imp. pago/lucro real) $\times 100$

\begin{tabular}{lccc}
\multicolumn{1}{c}{ SETOR } & Sociedade Anônima & Limitada & Empresa Individual \\
\cline { 2 - 4 } PRIMÁRIO & 25 & 8 & 12 \\
$\quad$ Agricultura e Criação & & & \\
SECUNDÁRIO & 20 & 23 & 16 \\
Indústria de Transf. & 8 & 15 & 10 \\
Ind. Extr. Mineral & 25 & 20 & 14 \\
Ind. de Construção & 20 & & $29 *$ \\
TERCIĀRIO & 9 & 24 & 18 \\
Transportes & 22 & 21 & 18 \\
ComunicaçDes & 12 & 22 & - \\
Comércio & 16 & 16 & 13 \\
Interm. Financeiros & 19 & $35 *$ & 23 \\
Serviços & & 24 & \\
\hline MEDIA GERAL & & & \\
\hline
\end{tabular}

Fonte:F. Rezende, $\mathrm{O}$ crescimento e a estrutura da receita e os coeficientes de carga tributária. In $O$ Imposto sobre a Renda das Empresas, org. por F. Rezende. Rio de Janeiro: IPEA/INPES, 1975. Ver pág. 35.

* O IRPJ era de $30 \%$ para o ano base de 1972, porém o autor levanta a hipótese de que taxas efet ivas maiores que essa podem ocorrer por conta de pagamentos com base em estimativas ou arbitramento do lucro.

** Imposto pago em 1972 sobre lucro real de 1971.

Embora os dados médios por tipo de organização jurídica permitam o levantamento de hipóteses relacionadas com o tamanho das empresas, a desagregação por setores não mantém este padrão em todos os casos. Assim, as sociedades anônimas da Agricultura e da Construção apresentam taxas efetivas mais altas do que 
as limitadas e/ou individuais. Porém, para os demais setores da Tabela 4 , as sociedades anônimas pagam sempre uma menor taxa eftiva.

A comparação intersetorial será feita apenas para as sociedades anônimas na suposição de que elas dominam cada um dos setores, especialmente nos setores industriais e do terciário. $O$ setor Agrícola apresenta uma alta taxa efetiva, bem acima da média nacional, o mesmo ocorrendo com o Setor de Construção. No Setor Secundário, a Indústria de Transformação, que é a parte mais importante, pagou uma taxa efetiva igual à média nacional. No Setor Terciário, os subsetores mais importantes, que são Comércio, Transportes e Serviços (ver Almeida e Silva), apresentaram taxas próximas da Indústria de Transformação.

Comércio, na verdade, está com do is pontos percentuais acima da Indústria de Transformação, o que pode ser considerado uma diferença pequena. Ainda em relação a Comércio, deve-se adicionar que as diferenças na taxa efetiva, segundo a organização jurídica das empresas, não são grandes, em comparação com alguns outros setores. Diferenças muito grandes ocorrem em Serviços, por exemplo.

O trabalho de F. Rezende faz também uma comparação internacional. Alguns países mais representativos e, em alguns casos, de nível de desenvolvimento parecido com o do Brasil, foram selecionados e incluídos na Tabela 5. As taxas efetivas, nesses paises, são de modo geral bem mais altas do que no Brasil. Entre os paises desenvolvidos listados, somente a Suíça apresenta uma taxa efetiva menor que a brasileira. Entre os países em desenvolvimento, há os casos extremos da lndia e da Indonésia, taxando o equivalente à metade dos lucros reais. Há naturalmente casos de taxação mais le. ve, como o Urııguai e a Nigéria.

F. Rezende chama atenção ainda pará o fato de que, de modo geral, as diferenças entre as taxas legais e as efetivas tendem a ser menores do que no Brasil. Isto pode estar significando uma gama muito grande de abatimentos, incentivos, etc., que criam tal diferencial no Brasil. Como foi visto acima, isto pode ser a causa dos diferenciais da taxa efetiva entre os setores e entre os tipos de empresa.

Em resumo, a carga tributária sobre os rendimentos do capital, se válida a presente hipótese de incidência total apenas do IRPJ, gira ao redor dos $20 \%$. Porém, a isso seria preciso adicionar os impostos que ainda seriam absorvidos por tais rendimentos quando de sua utilização. A comparação internacional mostra ain- 
da que, pelo critério da incidência apenas do IRPJ, os ganhos de capital são de modo geral menos taxados no Brasil. Setorialmente, não se observaram grandes diferenças entre os setores mais importantes, exceto para sociedades anônimas do setor agrícola. 0 comércio, contudo, estava alguns pontos percentuais acima da média nacional.

TABELA 5 - TAXAS LEGAIS E EFETIVAS DO IMPOSTO SOBRE A RENDA

DAS EMPRESAS EM DIFERENTES PAISES - 1968

\begin{tabular}{lcc}
\hline PAISES & TAXAS LEGAIS & TAXAS EFETIVAS \\
\hline Desenvolvidos & & \\
Estados Unidos & 52,8 & - \\
Canadá & 50,0 & 39,1 \\
Alemanha & 52,5 & 41,4 \\
Reino Unido & 45,0 & 38,7 \\
França & 50,0 & 45,5 \\
Sulça & 7,2 & 16,7 \\
Japão & 35,0 & 41,1 \\
& & \\
Em Desenvolvimento & & \\
México & 42,0 & 40,7 \\
Argentina & 33,0 & 21,8 \\
Colómbia & 36,0 & 43,4 \\
Venezuela & 50,0 & 28,1 \\
Uruguai & 21,0 & 15,7 \\
Paraguai & 25,0 & 24,4 \\
Nigéria & 50,0 & 11,2 \\
Rodésia & 36,2 & 34,9 \\
India & 60,0 & 57,1 \\
Indonésia & 60,0 & 48,5 \\
Cingapura & 40,0 & 20,4 \\
\hline
\end{tabular}

Fonte:F. Rezende, Op. Cit., pp. 33-4, o qual cita M.E. Kyrouz, For cign tax rates and tax bases. National Tax Journal, 28(1):6 61-80, mar. 1975.

\section{CONCLUSĀO}

O objetivo do presente trabalho foi o de clarificar a noção de carga tributária, procurando levar em consideração as possibilidades de transferência de impostos para frente. Foi preciso tal esclarecimento para que houvesse sentido em se falar sobre a carga tributária de um determinado setor da economia. Viu-se, porém, que é mais fácil falar em carga tributária para a economia como um todo ou para grupos de pessoas classificadas segundo a renda do 
que fálar sobre a carga de um setor. Mesmo assim, após a apresentação de dados sobre a carga tributária para o país, viu-se também a carga tributária por setores. Seguindo suposições usuais sobre transferência de impostos, usou-se a taxa efetiva do IRPJ como aproximação a essa carga tributária. Observou-se, porém, que tal estimativa ignora os impostos pagos indiretamente.

\section{BIBLIOGRAFIA}

O livro de Contador apresenta uma excelente discussáo, porém um pouco técnica, sobre transferéncia. O Capítulo 16 dos Musgrave é a melhor exposição sobre a noção de incidéncia, aqui chamada carga tributária.

ALMEIDA, Walderly J.M. de, e Maria da Conceição Silva. Dinâmica do Setor Serviços nc Brasil: Emprego e Produto. Rio de Janeiro: IPEA/INPES, 1973. (Ralatório de PesGisa, 18).

CONTADOR, Cláudio R. A Transferência do Imposto de Renda e Incentivos Fiscais no Brasil. Rio de Janeiro: IPFA/INPES, 1976. (Relatório de Pesquisa, 33).

ERIS, 1., et alii. A distribuição de renda e o sistema tributário no Brasil. In : Finanças Públicas. São Paulo: Pioneira/FIPE, 1983.

Fundação Getúlio Vargas. Regionalização das Transaçöes do Setor Público - 1975. Rio de Janeiro, 1980.

KYROUZ, M.E. Foreign tax rates and tax bases. National Tax Journal, EUA, 28(1):6180, mar. 1975.

LONGO, Carlos A. Nota sobre a evolução da carga fiscal no Brasil. Revista de Economia Política, 4(4): 124-134, out./dez./1984.

MUSgRAVE, Richard A., e Peggy B. Musgrave. Finanças Públicas: Teoria e Prática. Rio de Janeiro: Editora Campus; São Paulo: Ed. da Univ. de São Paulo, 1980.

REZENDE. Fernando. O crescimento e a estrutura da riceita e os cuaficientes da carga tributária. In: $O$ Imposto sobre a Renda das Empresas, org. por F. Rezende. Rio de Janeiro: IPEA/INPES, 1975. (Sêrie Monográfica, 19).

REZENDE, Fernando. Finanças Públicas. São Paulo: Atlas, 1979.

SANSON, João R. Conseqüéncias da substituiçáo do IVC pelo ICM sobre a renda real de consumidores nordestinos e sulistas. Anais do // Encontro Brasileiro de Econometria. Brasília: Sociedade Brasileira de Econometria, 1980. 